\title{
Research projects and capacity building
}

\author{
CM Breen ${ }^{1}$, JJ Jaganyi ${ }^{1}$, BW van Wilgen² and E van Wyk ${ }^{3^{*}}$ \\ ${ }^{1}$ Centre for Environment and Development, University of KwaZulu-Natal, Pietermaritzburg; Private Bag X01, Scottsville 3209, South Africa \\ ${ }^{2}$ CSIR Environmentek, PO Box 320, Stellenbosch 7599, South Africa \\ ${ }^{3}$ CSIR Environmentek, PO Box 395, Pretoria 0001, South Africa
}

\begin{abstract}
A World Bank long-term perspective study on Sub-Saharan Africa highlighted the need to build human and institutional capacity in virtually all sectors and countries. In South Africa, establishment of a democratic government in 1994 saw increased emphasis placed on capacity building. This led to the revision of policies and legislation directing human resources development. This emphasis on capacity development is reflected in procurement policies to the extent that it is increasingly difficult to successfully bid for funding from government and parastatal organisations unless there is both a plan and a commitment to capacity building in the previously marginalised sectors. There are currently no guidelines to support researchers in their attempts to support the intentions of legislation and policy. It has been assumed that researchers have the understanding and expertise to effectively promote capacity building. Under such conditions the expectations of research administrators are neither clearly structured nor are they understood by researchers. Not surprisingly, researchers often fail to meet the expectations of administrators. In an attempt to contribute towards developing a structured approach, this paper interprets what is meant by capacity building in the context of research projects. Based on this interpretation, reasonable and unreasonable expectations with respect to the extent to which capacity building can be achieved within a given project duration are discussed. A model is suggested, which would improve understanding and delivery and in doing so, achieve better congruence between expectations and outcomes.
\end{abstract}

Keywords: capacity building, research, change, performance, innovation

\section{Introduction}

A long-term perspective study (World Bank, 1991) has highlighted the need to build human and institutional capacity in virtually all sectors and countries in Sub-Saharan Africa. This need is exacerbated by the rapid rate of change in technology that increases the challenge of acquiring the knowledge and skills that enhance ability and capacity to adapt to change (Senge, 1990; Barth and Bartenstein, 1998; Davenport et al., 1998; Senge et al., 1999). It is against this appreciation of the need for capacity that the Foundation for Research Development (FRD, now the National Research Foundation, or NRF), established in 1984, was charged with the responsibility of promoting research and developing research capacity. In an effort to include people from disadvantaged backgrounds and institutions, it introduced the Research Development Programme in 1986. This was followed by the University Development Programme in 1992 and the Institutional Research and Development Programme in 1995.

Establishment of a democratic government in South Africa in 1994 saw increased emphasis placed on capacity building. This led to revision of approaches to research development (DACST, 1996a; b; Department of Education, 1995; South African Qualifications Authority, 2000; South African Government, 2000). The Water Research Commission(WRC), for example, requires researchers to specifically address capacity building in research proposals (Water Research Commission, 2000) and has also set up The Research Partnership Fund to promote research capacity building at historically disadvantaged universities and universities of technology.

* To whom all correspondence should be addressed.

巡+2712 841-3672; fax:+2712 841-3954; e-mail: evwyk@csir.co.za

Received 19 April 2004; accepted in revised form 10 August 2004.
Since the inception of these programs, the organisations concerned with research development have made significant advances in terms of defining critical elements in the development of research capacity. This progress is reflected in existing policies, strategies and guidelines around capacity building in research. However, these guidelines do not indicate how researchers should engage capacity building as a process at the level of the research project. Nor have the expectations they have of researchers been clearly articulated. Recent revisions of policy in the Southern African Development Community (SADC, 2000) and in South Africa reflect appreciation for the imperatives of integrated water resource management incorporating a shift in emphasis from supply to demand management. Since success in achieving equitable, efficient and sustainable use of limited water resources in the region is critically dependent upon informed stakeholders, strong emphasis is placed on capacity building in these policies.

Against this background, the WRC supported a research project (Van Wilgen et al., 2003) aimed at developing protocols for improving catchment management through enhanced stakeholder participation. The special emphasis on capacity building in this project and the funder's requirement for capacity building and for reporting on related progress, led the authors to seek improved understanding of how capacity building can be achieved in research projects. While the principal pathway of the project proceeded, the research team explored the theoretical underpinnings of capacity building as a parallel process. The intention was to propose a framework which would improve understanding and delivery and, in doing so, achieve better congruence between expectations and outcomes relating to capacity building in research projects.

This paper presents the results of our investigations and should be interpreted as a first step towards improving understanding of the contribution research projects make to capacity building. 


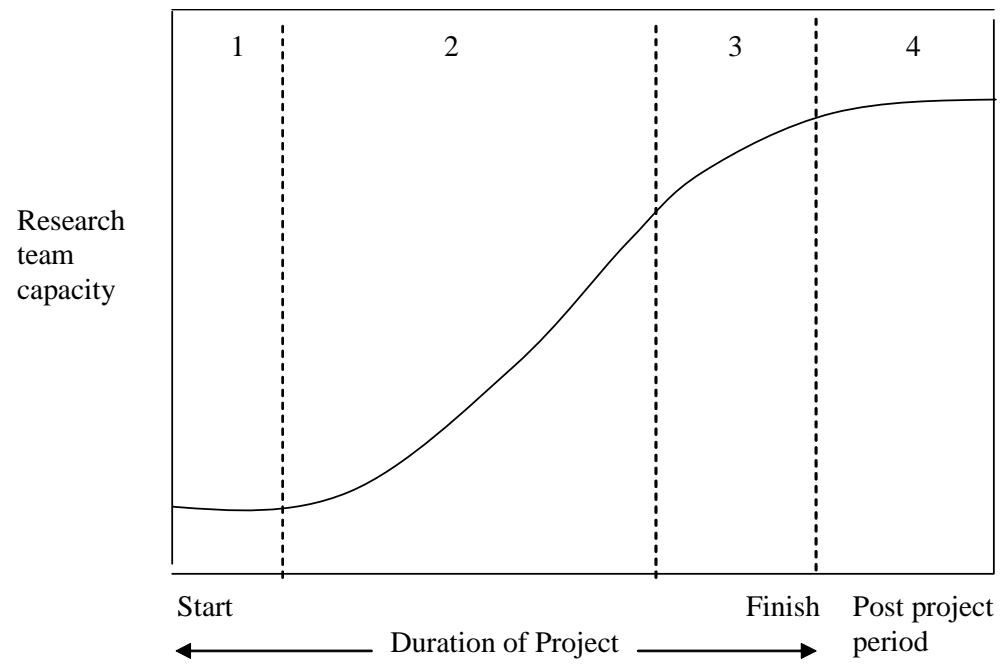

Figure 1

Hypothetical growth in research team capacity over the duration of a collaborative project. Phase 1-lag phase during orientation and achieving shared understanding of the problem. Phase 2-growth in capacity as new findings emerge. Phase 3-slow down as project approaches termination. Phase 4testing findings on peers through presentations and publications.

During this period diffusion and capacity building occurs external to the team but this is commonly restricted to peers.

\section{What is capacity building?}

Capacity building is a commonly used term that holds many different meanings for different people. Generally, however, it is understood to be conditional upon improving knowledge and changing people's behaviour so that they can make more informed decisions, adapt better to changing conditions and be more effective in carrying out decisions (Senge et al., 1999; McAllister and Vernooy, 1999; Boal, 1995; Eade, 1997). The realities of contemporary South Africa, however, are that capacity building is commonly equated with providing opportunities for individuals from previously marginalised sectors, especially given the pressure to address past inequities. This element of capacity building is acknowledged as necessary and urgent, but is this sufficient? Are 'head counts' and/or 'degree counts' of individuals from marginalised sectors, including gender, participating in research projects appropriate measures for capacity building? Much depends on how capacity building is defined and contextualised. Capacity building is not an end in itself; it is a means to improved efficiency of performance and productivity (Senge et al., 1999). The intention of capacity building supported through the national treasury is clearly improved national well-being. This suggests that however capacity building may be defined, if it occurs through state-funded research projects, it should take account of national interests that are wider than participation of individuals from previously marginalised sectors.

For our purpose, we have defined capacity building as 'a process whereby people are enabled to better perform defined functions either as individuals, through improved technical skills and or professional understanding, or as groups aligning their activities to achieve common purpose'. We envisage it as a personal growth process that leads to enhanced performance. As such, it is evident that capacity building is not an event, but rather a continuous process. Since many factors can retard the diffusion and adoption of knowledge, and its subsequent translation into action (Senge et al., 1999; The Department of Education, 1995) capacity building is typically a slow process occurring over time scales much longer than individual research projects.

The United Nations Development Programme (UNDP, 1995; 2002) for example, has suggested that 'a realistic time frame for organisational strengthening is over 10 years and it must be an ongoing generative learning process'. In this sense, research projects are relatively short-term 'events' in an ongoing process of capacity development. Clearly the expectations of capacity building in the context of research projects should be much different from those of the process over longer time scales.

McAllister and Vernooy (1999) have observed that outcomes of participatory research for natural resource management may be 'diffuse and long-term, and notoriously difficult to measure or attribute to a particular research project or activity'. This indicates that quite different measures may be appropriate for capacity building over the duration of a project and over the long term. Before measures for capacity building in projects can be defined it is necessary to understand the context of research projects.

\section{Context of research projects}

The purpose of research is to gain new insight and understanding so that we are better prepared to respond to changing circumstances (Senge et al., 1999; Platt 1964; Kreb, 1994). It is therefore a journey into the unknown. Consequently, it should not be assumed that the researcher(s) have at the start of a project, the new knowledge available for diffusion into a wider sector.

Typically, where researchers are to collaborate in a project, they first have to build shared understanding (Senge, 1990; Senge et al., 1994; 1999; Schein, 1996) of the research problem (see Fig. 1), then they have to implement the project and it is commonly only towards the end of the project that coherent findings and interpretations emerge. These may have to be tested amongst peers before promoting wider diffusion. The project cycle is often completed before this can take place with the result that whilst team members may have gained new, shared skills, insight and knowledge, there has been little wider diffusion of new insights and knowledge. With termination of the project, motivation and resources required to sustain strategic advances decline, diffusion becomes a passive rather than active process, and diffusion, adoption and innovation are accordingly slow (McAllister and Vernooy, 1999).

It should, however, also not be assumed that this provides good justification for not actively engaging a wider sector at the start of the project. If intended adopters share an understanding of the need for and purpose of the research, they will be better prepared for the outcomes, and diffusion and adoption will be enhanced (McAllister and Vernooy, 1999; Chambers, 1997; NEDA, 1998; Murphree, 1993). The issue, therefore, is not when strategic partners in the knowledge innovation chain (Fig. 2) should be engaged but rather establishing an ongoing and dynamic relationship with them (Barth and Bartenstein, 1998). Acknowledging their position, roles and responsibilities in the knowledge innovation chain assists researchers in identifying strategic partners in fostering the diffusion and transformation of knowledge for application (Davenport et al., 
Figure 2

The knowledge innovation chain requires

that strong alliances

exist between sites of

basic research, those

that transform new

knowledge for

application and those

that apply knowledge in

development of new

products, processes and

services. There are

delays in diffusion,

adoption and use of

knowledge moving in

both directions.
Knowledge innovation
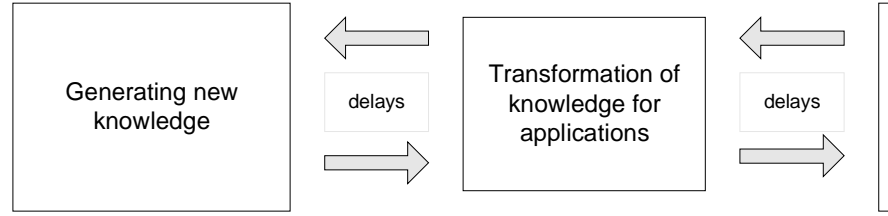

Application into new products, processes and services

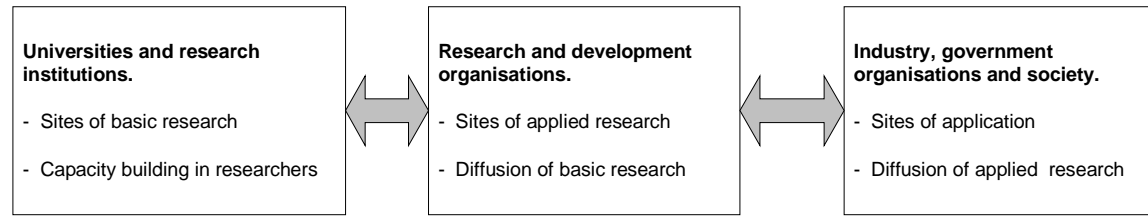

1998; Powers, 1995; Brown and Gray, 1995; Wenger, 1998; Brown and Duguid, 2000; Cullen et al., 1999; Dixon, 2000; Grayson et al., 2000). This is a reciprocating process in which researchers are continually informed by strategic partners. The implication here is that it is a reasonable expectation of researchers that they form and sustain strategic alliances with individuals and organisations proximally located along the knowledge innovation chain. The substance of these alliances is that researchers and strategic partners have a shared understanding of the rationale, approach and anticipated outcomes of the research and that together they strive to create and sustain environments for learning. The implication here is that capacity building has more to do with the way we do things than what we do. This understanding permits definition of targets and measures for capacity building.

\section{Indicators for capacity building}

We are suggesting that in the greater national vision, capacity building is reflected in the diffusion, transformation and application of new knowledge and skills. Certain enabling conditions are essential pre-requisites for this to happen efficiently and effectively. The need to create and sustain 'enabling conditions' is implied (SADC, 2000) and acknowledged at regional level (SADC, 2001). Because capacity building occurs through the development and maintenance of long-term relationships which are marked by shifts in strategy and attitudes, those wishing to build capacity need to be continually observing, reflecting on, changing and improving those relationships (Senge et al., 1999; Van Wilgen et al., 2003; UNDP, 1995; CDRA, 1995; Stokking et al., 1999). This convinces us that whilst numbers of people (including race and gender) gaining higher degrees and papers published in peer-reviewed journals may provide some measure of capacity building, they do not measure the extent to which fundamental enabling conditions have been fostered. Indeed, they may provide incentives to direct and focus effort away from achieving enabling conditions necessary for activating the knowledge innovation chain. Were assessments of researchers to include indicators of enabling conditions it seems probable that researchers would be more committed to a process of capacity building that is better aligned with national intentions. Examples of enabling conditions and measurable indicators are shown in Table 1.

\section{Organisational support for capacity building}

Once we adopt a paradigm for capacity building that reflects strategic alliances interacting in a learning environment that is supported by enabling conditions, we appreciate that capacity building in research projects is not the sole responsibility of the researchers. The responsibility must be shared amongst those individuals and institutions who promote research (for example, research funding agencies such as the WRC and NRF) (Johnson and Walker, 2000; Keen and Stocklemayer, 1998; Bebbington and Riddell, 1995), those who conduct research, and those strategic partners proximally positioned on the knowledge innovation chain (Maselli and Sottas, 1996). The implication is that individuals, and through them, their organisations, have to redefine their roles and responsibilities so as to jointly create the learning environment and enabling conditions in which capacity building can occur. We should therefore require and measure capacity building in participating organisations and individuals over and beyond the duration of projects.

Senge et al. (1999) use the term 'profound change' to describe organisational change that combines inner shifts in peoples' values, aspirations and behaviour with outer shifts in processes, strategies, practices and systems. The combination of these inner and outer shifts enables organisations (research teams, support agencies, strategic partners) to build their capacity for doing things in new ways and so to sustain change after a project has run its course. It would therefore be important to develop and apply indices for measuring these inner and outer shifts.

\section{Change and resistance to change}

Building capacity involves change and personal transformation and whilst people may not resist change, they do resist being changed (Senge et al., 1999; Strebel, 1996; Breen, 1999). This informs us that relying on passive processes to effect personal transformation is likely to lead to situations in which resistance frustrates progress 


\begin{tabular}{|c|c|}
\hline $\begin{array}{r}\text { TA } \\
\text { Examples of enabling conditions and measurable indica } \\
\text { efficiently where enabling conditions are weak or ab } \\
\text { process approach to capacity building (see Fig. } 1 \text { and } \\
\text { ability to resp }\end{array}$ & $\begin{array}{l}\text { SLE } 1 \\
\text { tors for capacity building. Capacity building cannot occur } \\
\text { sent. Enabling conditions and indicators here reflect a } \\
\text { 3) and it suggests measures that will measure society's } \\
\text { ond to change. }\end{array}$ \\
\hline Enabling conditions & Indicators \\
\hline Individual willingness to change & Attitudes are open and roles and responsibilities change \\
\hline $\begin{array}{l}\text { Shared understanding of, and commitment to capacity building } \\
\text { amongst individuals }\end{array}$ & $\begin{array}{l}\text { Evidence of team work, collaboration, enthusiasm and willingness } \\
\text { to commit to capacity building }\end{array}$ \\
\hline $\begin{array}{l}\text { Continuous observation, reflection, changing and improving } \\
\text { relationships }\end{array}$ & Evaluation of self, teams and project \\
\hline Openness to learning & Response to new ideas, adoption of new approaches \\
\hline $\begin{array}{l}\text { Opportunities for participation, learning and personal growth } \\
\text { at all levels }\end{array}$ & $\begin{array}{l}\text { Evidence for involvement beyond confines of personal interests } \\
\text { and disciplines }\end{array}$ \\
\hline Mutually supportive long-term relationships & Resources and information are shared, collaborative initiatives \\
\hline $\begin{array}{l}\text { Organisational environments that support continual innovation } \\
\text { and knowledge generation }\end{array}$ & Incentives promote collaboration and strategic alliances \\
\hline $\begin{array}{l}\text { Resources available to establish and sustain an active process } \\
\text { of learning }\end{array}$ & Institutional policies and practices, resource allocation \\
\hline Active process for transformation & Personnel implement explicit policies and procedures \\
\hline Leadership that can sustain creative tension and shared vision. & Conflict management, team building, co-evolution of perspectives \\
\hline Opportunities for practical engagement & $\begin{array}{l}\text { Enhanced personal results, networks of committed people, } \\
\text { new practices, improved results }\end{array}$ \\
\hline $\begin{array}{l}\text { Strategic alliances amongst universities, research institutions, } \\
\text { development organisations, industry, government, society } \\
\text { and funding agencies }\end{array}$ & Evidence of sharing roles and responsibilities for common purpose \\
\hline Committed local level or line leaders & Job descriptions, performance indicators, staff allocation \\
\hline Recognition and reward for personal results & Incentives support intentions \\
\hline Good governance & $\begin{array}{l}\text { Evidence for efficiency, transparency, accountability, adaptive } \\
\text { management, generative learning }\end{array}$ \\
\hline
\end{tabular}

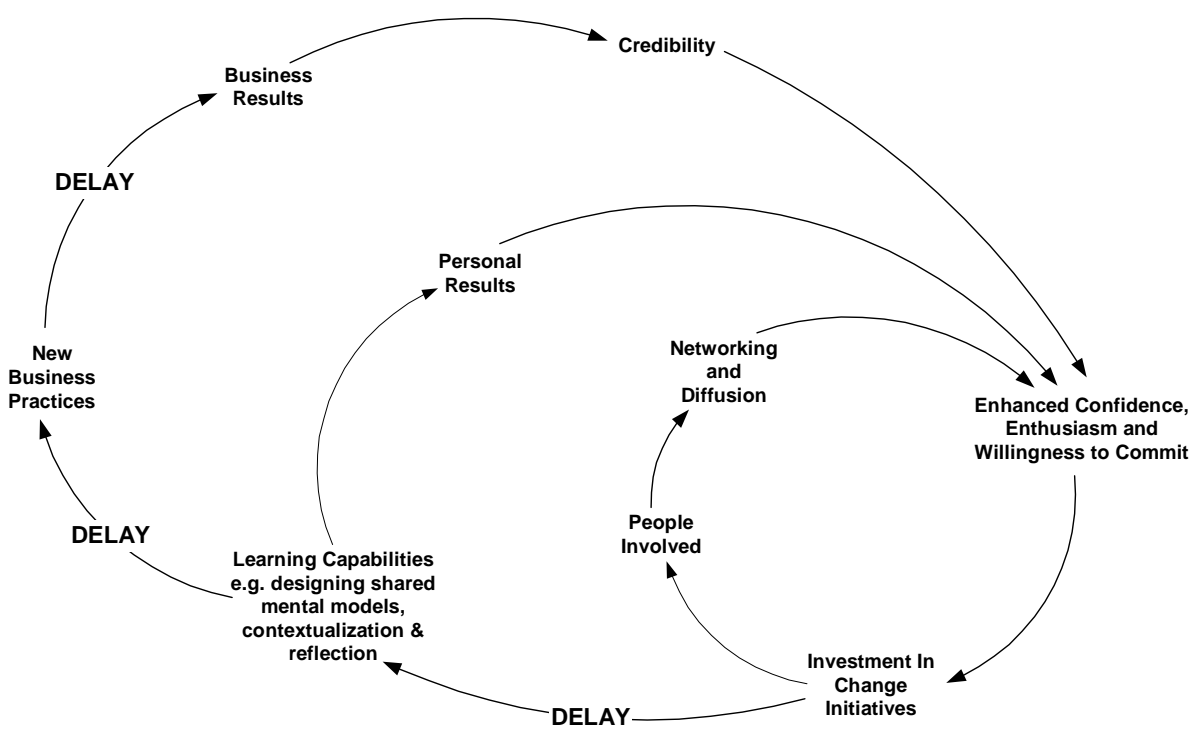

Figure 3

Investment in initiatives leads to new learning capabilities and personal results; More people become involved and aware through informal networking; Eventually the learning capabilities generate new business practices,

business results, and increased credibility. Each of these increases willingness to commit to change initiatives, leading to further investment in change initiatives. (Adapted from Senge et al., 1999). 
with capacity building (Goodman, 1999; Champy, 1995; Kotter, 1995). We need to invest resources to establish and sustain an active process, and we need to appreciate what motivates personal transformation and hence capacity building. Institutional capacity building strongly reflects the extent to which personal transformation has occurred and continues to occur (Kleiner, 1996; Mirvis and Berg, 1997).

Senge and his colleagues (1999) have illustrated how investment in change initiatives, knowledge diffusion, willingness to commit, personal results and business results are related, and how delays slow the process. The model (Fig. 3) can be applied at a range of scales and in quite different situations. Collaborative research provides an illustration.

The model in Fig. 1 suggests a lag phase as a 'team' is created from researchers of different disciplines and experiences. This requires an 'investment in change', 'getting people involved', 'networking and diffusing' current knowledge and building 'confidence, enthusiasm and willingness to commit' (Fig. 3). This leads to 'learning capabilities' and new 'personal results' which reinforce 'enthusiasm and willingness to commit'. A rapid growth in new knowledge and capacity arises (Fig. 1). In time this may be expressed in research findings and results which lead to increased credibility (Fig. 3). Inherent delays slow the process so that not all outcomes may be achieved within the duration of a typical project cycle. If personal results are achieved, recognised and rewarded, then individuals desire to sustain the process and greater levels of results are achievable. This desire of individuals to sustain the process leads to capacity building beyond the termination of the project.

The process is vulnerable if investment is inadequate and if incentives are inappropriate (Bebbington and Riddell, 1995). Project design should, therefore, pay particular attention to determining the required level of investment in change initiatives, and to incentives that seek to sustain enthusiasm and willingness to commit. Clearly these will emphasise issues in addition to those used more traditionally (e.g. publications in peer-reviewed journals).

\section{Strategic directions}

This analysis suggests that researchers, research funders and potential funders in knowledge transformation and application do not have a shared understanding and formulation of what capacity building is, nor how each should engage the process to achieve broader national intentions. It is further suggested that because of this, there is insufficient investment in the process and the incentives and performance indicators do not direct commitment to capacity building. The present research funding and operating environments neither provide nor enable researchers to commit to capacity building as we understand it. Strategic interventions are urgently required. These are considered at two levels, namely corporate management and research project management.

It is the responsibility of corporate management to develop the following policies and strategies:

- Provide clear guidance for researchers, research funders and strategic partners

- Invest in establishing and sustaining the enabling environments for capacity building

- Establish appropriate incentives and performance criteria

- Ensure auditing and learning.

At research project management level, it is necessary to:

- Identify and engage the individuals and institutions which determine the nature, direction and rate of transformation and capacity building
- Build a shared appreciation of the national imperative of capacity building and the role of research therein

- Construct a framework (e.g. knowledge innovation chain) that helps articulate intentions and align behaviours

- Define the transformation process(es) to be engaged

- Identify and define capacity building needs and intentions

- Determine the need for preparatory forms of capacity building to increase responsiveness to research outcomes and diffusion from the project. If appropriate, build capacity using currently available knowledge and best practice

- Develop within the project team the capacity to influence the transformation process

- Engage the transformation process at individual and institutional level using enhanced team capacity. This should continue beyond the term of the project

- Put in place a long-term supportive and generative learning process.

We contend that it is necessary for policy makers and research funders to define the context in which they perceive research projects contributing to capacity building. At present this context is poorly defined with the result that neither researchers nor research funders have clarity on what they should be striving to achieve. We suggest that the knowledge innovation chain provides a useful model for contextualising the role of capacity building in research projects. Should such a model be adopted it would need to be supported by greater commitment by funders and administrators to creating and sustaining enabling conditions. A revision of incentives and performance measures for researchers would be desirable as greater direction and emphasis is given to strategic alliances along the knowledge innovation chain.

\section{Acknowledgements}

We sincerely thank the Water Research Commission for funding the research that led to the production of this manuscript, and Cheryl Lombard (NRF) for constructive comments.

\section{References}

BARTH TJ and BARTENSTEIN J (1998) Fostering a learning, innovative government: The role of academic/practitioner collaboration. Public Man. 27 21-26.

BEBBINGTON A and RIDDELL R (1995) Donors, Civil Society and Southern Ngos: New Agendas, Old Problems. London: ODI.

BOAL A (1995) The Rainbow of Desire: The Boal Method of Theatre and Therapy. London, Routledge.

BREEN CM (1999) CHANGE: A strategic leadership issue for river management. Integrated Management of River Ecosystems: An international experience. Proc. Kruger Park Rivers Research Programme (KNPRRP) Conference, 10-11 August. Kruger National Park, Berg-en-dal, South Africa. (http: //www.ccwr.ac.za/ KNPRRP/).

BROWN JS and DUGUID P (2000) Balancing Act: How to capture knowledge without killing it. Harvard Bus. Rev. May-June. 3-80.

BROWN JS and GRAY ES (1995) The People are the Company. Fast Company 1 (1) 78. November.

CHAMBERS R (1997) Whose Reality Counts? Putting the First Last. Intermediate Technology Publications, London, UK.

CHAMPY J (1995) Reengineering: A light that failed. Across the Board 32 (3) 27-31.

COMMUNITY DEVELOPMENT RESOURCE ASSOCIATION (CDRA) (1995) Capacity-Building: Myth or Reality? Community Development Resource Association, Annual Report 1994/1995, Woodstock, South Africa. 
CULLEN PW, NORRIS RH, RESH VH, REYNOLDSON TB, ROSENBERG D and BARBOUR MT (1999) Collaboration in Scientific Research: A critical need for fresh water ecology. Freshwater Biol. 42 131-142.

DAVENPORT TH, DE LONG DW and BEERS MC (1998) Successful knowledge management. Sloan Manage. Rev. 39 43-57.

DEPARTMENT OF ARTS, CULTURE, SCIENCE AND TECHNOLOGY (DACST) (1996a) White Paper on Science \& Technology: Preparing for the $21^{\text {st }}$ Century. Department of Arts, Culture, Science and Technology. 4 September. Pretoria, South Africa.

DEPARTMENT OF ARTS, CULTURE, SCIENCE AND TECHNOLOGY (DACST) (1996b) White Paper on Arts, Culture and Heritage: All our Legacies, our Common Future. Department of Arts, Culture, Science and Technology. 4 June. Pretoria, South Africa.

DEPARTMENT OF EDUCATION (1995) The South African Qualifications Authority Act. Pretoria, South Africa.

DIXON NM (2000) Common knowledge. How organizations thrive by sharing what they know. Harvard Business School Press, Boston. 188 pp.

EADE D (1997) Capacity Building - An Approach to People Development. Oxfarm, UK.

GOODMAN M (1999) Limits ahead: Using the 'limits to growth' dynamic to meet the challenges of profound change effectively. In: Senge P, Kleiner A, Roberts C, Ross R and Smith B (eds.) A Fifth Discipline Resource: The Dance of Change. London: Nicholas Brealey Publishing. 60-64.

GRAYSON R, EWINGS, ARGENT R, FINLAYSON B and MCMAHON $\mathrm{T}$ (2000) On the adoption of research and development outcomes in Integrated Catchment Management. J. Environ. Manage. 7 $147-157$.

JOHNSON A and WALKER D (2000) Science, communication and stakeholder participation for integrated natural resource management. J. Environ. Manage. 7 82-90.

KEEN M and STOCKLEMAYER S (1998) Communicating Research. An overview of communication efforts of rural industry research funding bodies. RIRDC Publication 99/54. Canberra, Australia.

KLEINER A (1996) The Age of Heretics. London: Nicholas Brealey Publishing.

KOTTER JP (1995) Leading Change: Why transformation efforts fail. Harvard Bus. Rev. March/April 59.

KREB CJ (1994) Ecology: The Experimental Analysis of Distribution and Abundance $\left(4^{\text {th }}\right.$ edn.). Harper Collins College Publishers, New York, USA.

MASELLI D and SOTTAS B (eds.) (1996) Research Partnerships for Common Concerns. Hamburg: LIT Verlag.

McALLISTER K and VERNOOY R (1999) Action and Reflection: A Guide for Monitoring and Evaluating Participatory Research. International Development Research Co-operation (IDRC). CBNRM, Programs Branch, IDRC, P.O. Box 8500, Ottawa, Ontario, Canada K1G 3H9.

MIRVIS PH and Berg DN (eds.) (1997) Failure in Organization Development and Change: Cases and Essays for Learning. New York: John Wiley and Sons.

MURPHREE MW (1993) Communities as resource management institutions. Gatekeeper Series (No. 30) International Institute for Environment and Development, Durban.

NATIONAL RESEARCH FOUNDATION (NRF) (1986) Research Development Programme. National Research Foundation, Pretoria, South Africa.

NATIONAL RESEARCH FOUNDATION (NRF) (1992) University Development Programme. National Research Foundation, Pretoria, South Africa.
NATIONAL RESEARCH FOUNDATION (NRF) (1995) Institutional Research and Development Programme. National Research Foundation, Pretoria, South Africa.

NETHERLANDS DEVELOPMENT ASSISTANCE (NEDA) (1998) Policy Priorities for Netherlands Development Assistance: Water for the Future-Integrated Water Resources Management. Ministry of Foreign Affairs, The Hague, Netherlands.

PLATT JR (1964) Strong inference. Sci.146 347-353.

POWERS VJ (1995) The work information network. In: 'Corporate Networks' in Continuous Journey Magazine. April. 34.

SADC (2001) Southern Africa Development Community. Protocol on Fisheries. Article 4, Principle (3). Signed at the 21st Summit of SADC Heads of State. Blantyre, Malawi 12-14th August. Also see Water Sector Co-ordinating Unit, http://www.sadcreview.com.

SADC (2000) Revised Protocol on Shared Water Courses in the Southern African Development Community-SADC. Article $2 \mathrm{Ob}$ jective (e) 4. Signed $7^{\text {th }}$ August.

SCHEIN EH (1996) The three cultures of management. Sloan Management Rev. (Fall). 9-20.

SENGE P (1990) The Fifth Discipline: The Art and Practice of the Learning Organization. New York: Doubleday/Currency.

SENGE P, KLEINER A, ROBERTS C, ROSS R and SMITH B (1999) A Fifth Disciple Resource: The Dance of Change. London: Nicolas Brealey Publishing.

SENGE P, KLEINER A, ROBERTS C, ROSS R and SMITH B (1994) The Fifth Discipline Fieldbook: Strategies and Tools for Building a Learning Organization. London: Nicholas Brealey Publishing.

SOUTH AFRICAN GOVERNMENT (2000) The South African Skills Development Act, 1998 (Act No 97 of 1998) Amendment of a list of and scope of coverage of sector education and training authorities, No. 265, 20 March 2000. Government Notice No. 21012 (3).

SOUTH AFRICAN QUALIFICATIONS AUTHORITY (SAQA) (2000) The National Qualifications Framework and Curriculum Development. (A report produced in May 2000 and funded by the European Union under the European Programme for Reconstruction and Development). South African Qualifications Authority (SAQA), Brooklyn, Pretoria.

STOKKING K, VAN AERT L, MEIJBERG W and KASKENS A (1999) Evaluating Environmental Education. IUCN, Gland, Switzerland and Cambridge, UK (IUCN Publications Services Unit info@books.iucn.org or www.iucn.org.

STREBEL P (1996) Why do employees resist change? Harvard Bus. Rev. May/June 86.

THE WORLD BANK (1991) The African Capacity Building Initiative: Toward Improved Policy Analysis and Development Management. The International Bank for Reconstruction and Development/ the World Bank. Washington DC, USA.

UNITED NATIONS DEVELOPMENT PROGRAMME (UNDP) (1995) United Nations Development Programme: Sustainable Human Development. New York.

UNITED NATIONS DEVELOPMENT PROGRAMME (UNDP) (2002) Human Development Report. Oxford and New York.

VAN WILGEN BW, BREEN CM, JAGANYI JJ, ROGERS KH, ROUX DJ, SHERWILL T, VAN WYK E and VENTER F (2003) Developing Principles and Processes for Supporting Stakeholder Participation in Integrated River Management. Water Research Commission (WRC) Report no. 1062/1/03. Pretoria, South Africa.

WATER RESEARCH COMMISSION (WRC) 2000 Project Guidebook. Section 5: Opportunities for Capacity Building. http:// www.wrc.org.za/wrcprojects/wrcguidebook/

WENGER E (1998) Communities of Practice: Learning, Meaning, and Identity. New York: Cambridge University Press. 